\title{
Children and Situation Models of Multiple Events
}

\author{
Pirita Pyykkönen \\ Saarland University
}

\author{
Juhani Järvikivi \\ Max Planck Institute for Psycholinguistics and \\ University of Helsinki
}

\begin{abstract}
The present study demonstrates that children experience difficulties reaching the correct situation model of multiple events described in temporal sentences if the sentences encode language-external events in reverse chronological order. Importantly, the timing of the cue of how to organize these events is crucial: When temporal subordinate conjunctions (before/after) or converb constructions that carry information of how to organize the events were given sentence-medially, children experienced severe difficulties in arriving at the correct interpretation of event order. When this information was provided sentenceinitially, children were better able to arrive at the correct situation model, even if it required them to decode the linguistic information reversely with respect to the actual language external events. This indicates that children even aged 8-12 still experience difficulties in arriving at the correct interpretation of the event structure, if the cue of how to order the events is not given immediately when they start building the representation of the situation. This suggests that children's difficulties in comprehending sequential temporal events are caused by their inability to revise the representation of the current event structure at the level of the situation model.
\end{abstract}

Keywords: situation model, language acquisition, event structure, language comprehension

The world is a flux of sequential events that need to be ordered to make sense of what happened when. People tend to store these events in memory in chronological order (A. Anderson, Garrod, \& Sanford, 1983; Mandler, 1986; Radvansky, Zwaan, Federico, \& Franklin, 1998; van der Meer, Beyer, Heinze, \& Badel, 2002; Zwaan, 1996). However, interpreting the event order from a text and storing it can be challenging, as language does not always encode events chronologically, but instead in reverse order to what happened in real life, as in Event 1 below. Furthermore, information as to how to order the events can be provided relatively late in the sentence, for example, by placing the temporal conjunction in the sentence-medial position.

Event 1: Mary wrote a letter after she baked cookies.

Irrespective of how events are encoded in language, adults typically are capable of achieving a coherent situation model of the event orders (Claus \& Kelter, 2006; Gennari, 2004; Münte, Schiltz, \& Kutas, 1998). However, earlier studies have demonstrated that children even aged 7-12 sometimes fail to reach the correct interpretation of temporal sentences (e.g., Amidon, 1976;

This article was published Online First October 3, 2011.

Pirita Pyykkönen, Department of Computational Linguistics, Saarland University, Germany; Juhani Järvikivi, Max Planck Institute for Psycholinguistics, Nijmegen, the Netherlands and Institute of Behavioural Sciences, University of Helsinki, Finland.

The study was supported by Academy of Finland Grant No. 213731 awarded to Pirita Pyykkönen and Grant No. 106418 awarded to Juhani Järvikivi. We also thank all the schools and pupils who participated in our experiment.

Correspondence concerning this article should be addressed to Pirita Pyykkönen, FR 4.7 Psycholinguistics, Department of Computational Linguistics, Saarland University, Building C7.1, 66041 Saarbrücken, Germany. E-mail: pirita@CoLi.Uni-SB.DE
Feagans, 1980; Pyykkönen, Niemi, \& Järvikivi, 2003; Trosborg, 1982). However, these studies have not succeeded in capturing the causes for the difficulties completely. The present study demonstrates that children's failure to create the correct event-order representation of multiple events does not lie only in the situations when language encodes the events in reverse chronological order; importantly, children have particular difficulties also in revising their situation models when the cue of how to order the events is given only later sentence-medially and indicates reverse chronological encoding.

\section{Earlier Explanations for Children's Difficulties}

Studies of children's understanding of temporal structures have proposed the following explanations for their observed difficulties in reaching the correct interpretation: (a) The relative semantic ease of the conjunction "before" makes comprehension easier than "after" (Amidon, 1976; Clark, 1971; Feagans, 1980); (b) Presenting two events in subsequent main clauses facilitates comprehension compared with other sentence structures suggesting that clause type plays an important role (Amidon \& Carey, 1972); (c) Comprehension is facilitated when language encodes events in the same order in which they have occurred in real life, indicating that children rely on the iconicity of linear order (e.g., Amidon, \& Carey, 1972; Clark, 1971; Pyykkönen et al., 2003).

Clark (1971) found that children comprehended before better than after and explained this by suggesting that semantic + features are learned prior to -features; whereas before carries values + time, -simultaneous and + prior, after carries values + time, -simultaneous and -prior, having one more negative component and thus making after more difficult to comprehend than before. However, whereas some have shown that children understand after better than before (Amidon, 1976; Feagans, 1980), others have observed no differences between the conjunctions 
(Amidon \& Carey, 1972; French \& Brown, 1977; Friedman \& Seely, 1976; Johnson, 1975). Even though both clause orders have been used in some studies, either a main clause followed by subordinate clause or vice versa, what has not been considered is the placement of the conjunction as crucial for the final interpretation. Although some researchers have collapsed their data over the clause orders when describing the results (e.g., Amidon, 1976; French \& Brown, 1977; Johnson, 1975), others have discussed the sentence-initial and sentence-medial conjunctions with respect to their function in describing events in chronological or reverse chronological order-not the placement of the conjunction itself (Clark, 1971; cf. Trosborg, 1982).

Amidon and Carey (1972) found that sentences like "Move a blue plane first; move a red plane last" were easier to interpret than "Move a blue plane before/after you move a red plane," as indicated by children dropping the subordinate clause from the actingout task. They argued that the degree of difficulty depends on the type of clause: Sequentiality is more difficult to interpret from complex than from simplex structures (see also Berman \& Slobin, 1994). However, Pyykkönen et al. (2003) failed to find any difference in performance between temporal sentences that contained either subordinate clauses or so-called converb constructions (nonfinite verb structures that serve to express adverbial subordination, i.e., notions such as after and while; Haspelmath, 1995), despite the former being transparently marked with a conjunction and the latter lacking an explicit conjunction. ${ }^{1}$

Some studies have noted that children find it more difficult to comprehend sentences in which events are encoded in reverse chronological order, like in Event 1 above (e.g., Amidon \& Carey, 1972; Clark, 1971; Pyykkönen et al., 2003; cf. Amidon, 1976). This suggests that iconicity, that is, assuming one-to-one correspondence between the order of events in the sentence and in the world, has an effect on children's comprehension. Similarly, studies with adults have shown temporary difficulties when comprehending events given in reverse chronological order: Using eventrelated brain potentials, Münte et al. (1998) showed different brain responses to sentences starting with beforelafter, indicating that adults start building the representation of temporal subordinate clauses already at the sentence-initial conjunction and face temporary memory constraints when comprehending the reverse event order. Importantly, even though reverse order has been found to be difficult, studies have considered only one clause order, and thus the findings are open to other suggested explanations as well.

\section{The Present Study}

We investigated in the present study children's understanding of multiple events, because they are indicative of the interface between how the events are perceived as taking place in the world and how they are coded and interpreted linguistically. We asked whether the position (i.e., when in the sentence the relative ordering information of the events is given) would predict children's difficulties in achieving the correct situation model of multiple events. If the memory constraints proposed by Münte et al. (1998) were enough to explain the observed difficulties in comprehension, it can be assumed that the reverse chronological order would be more difficult to comprehend than the chronological in general. However, it has been established that first-mentioned entities serve as an important basis for building the situation model (e.g., Gern- sbacher, 1989, 1990). Therefore, it can be expected that if the ordering information were given sentence-initially, children would have less difficulties building the correct situation model, even though it would require reverse interpretation of the temporal events.

By systematically using both temporal subordinate clauses and converb constructions (i.e., nonfinite structures that mark temporal relations without an explicit conjunction), we were able to test the extent to which children's difficulties would be explainable from the use of a certain conjunction or type of temporal construction. As discussed earlier, some studies have found that before is learned earlier than after, or vice versa, whereas differences have not been found in some studies. In addition, it could be assumed that because converb constructions do not explicitly differentiate the first and the second event from each other (unlike subordinate clauses that do), the situation model could be more difficult to construct from sentences containing converb constructions than from sentences containing subordinate clauses. This could partly be due also to their greater linguistic complexity: Unlike subordinate clauses that consist of strings of free morphemes that code the time relation lexically and transparently, converb constructions consist of a morphologically complex nonfinite verb form that codes time (and person) as a string of fused suffixal elements attached to a bound base morpheme. As linguistic complexity has been shown to affect acquisition (e.g., Diessel, 2004), this might show in poorer performance on converbs than subordinate constructions.

As half of the converb constructions depicted simultaneous rather than sequential events, it allowed us to assess whether sequential ordering would be more difficult per se for children (Amidon \& Carey, 1972; Feagans, 1980).

\section{Method}

\section{Participants}

One hundred thirty-two children from Grades 2 (48), 4 (48), and 6 (36) from the schools Kerttulinkoulu and Normaalikoulu in Turku, Finland, participated. All were native speakers of Finnish and used only Finnish at home with their parents. Their mean ages were 8.5 years, 10.58 years, and 12.5 years, respectively.

\section{Materials}

Two types of temporal constructions in Finnish were used: (a) sentences with temporal subordinate clauses and (b) temporal converb constructions (see Table 1). Both were presented in two

\footnotetext{
${ }^{1}$ Converbs are nonfinite verb forms that in many languages express adverbial subordination (Haspelmath, 1995) —in other words, many common adverbial functions like time, manner, place, instrument, and cause, but using a verbal instead of a nominal form. Converbs are often, and in Finnish in particular, used to express the same relations as notions like "when," "after," "before," and “while." In Haspelmath's (1994) words, they are "verbal adverbs" (p. 153). Like other nonfinite verb forms, converbs are not marked for categories such as tense, mood, aspect, person, and number, and, thus, they cannot function as the main predicates of independent sentences. As an example of a converb construction in English, traditionally referred to as gerunds, consider "Having read the book, Paul returned to the class," which expresses essentially the same meaning as "After Paul read the book, he returned to the class."
} 
Table 1

Example Sentences With Subordinate Clauses and Converb Constructions Used in the Experiment

\begin{tabular}{|c|c|c|c|c|}
\hline Sentence & Condition & Conjunction & Clause order & Interpretation \\
\hline \multicolumn{5}{|l|}{ Temporal subordinate clauses } \\
\hline \multicolumn{5}{|l|}{ "Ilkka luki kirjeen ennen kuin meni kouluun } \\
\hline \multirow{3}{*}{\multicolumn{5}{|c|}{$\begin{array}{l}\text { Ilkka luki kirjeen sen jälkeen kun meni kouluun } \\
\text { "Ilkka read the letter after he went to school." } \\
\text { Ennen kuin Ilkka luki kirieen, hän meni }\end{array}$}} \\
\hline & & & & \\
\hline & & & & \\
\hline \multicolumn{5}{|l|}{$\begin{array}{l}\text { Ennen kuin llkka luk1 kırjeen, han menı } \\
\text { kouluun }\end{array}$} \\
\hline \multicolumn{5}{|l|}{$\begin{array}{l}\text { "Before Ilkka read the letter, he went to } \\
\text { school." }\end{array}$} \\
\hline \multirow{2}{*}{\multicolumn{5}{|c|}{$\begin{array}{l}\text { Sen jälkeen kun Ilkka luki kirjeen, hän meni } \\
\text { kouluun }\end{array}$}} \\
\hline & 4 & After & $\mathrm{S}+\mathrm{M}$ & Chronological \\
\hline & Condition & Tense & Clause order & Interpretation \\
\hline \multicolumn{5}{|l|}{ Temporal converb constructions } \\
\hline Mari teki läksyjä Tarjan katsoessa televisiota & 5 & Present & $\mathrm{M}+\mathrm{C}$ & Simultaneous \\
\hline \multicolumn{5}{|l|}{ "Mari did homework Tarja watching the TV." } \\
\hline \multicolumn{5}{|l|}{$\begin{array}{l}\text { [Mari do-past-progr. home-work, Tarja-gen } \\
\text { watch-nonfinite-pres TV-ptv] }\end{array}$} \\
\hline Mari teki läksyjä Tarjan katsottua televisiota & 6 & Past & $\mathrm{M}+\mathrm{C}$ & Reverse \\
\hline \multicolumn{5}{|l|}{$\begin{array}{l}\text { "Mari did homework, Tarja having watched the } \\
\text { TV." }\end{array}$} \\
\hline \multicolumn{5}{|l|}{$\begin{array}{l}\text { [Mari do-past-progr. home-work, Tarja-gen } \\
\text { watch-nonfinite-past TV-ptv] }\end{array}$} \\
\hline Tarjan katsoessa televisiota Mari teki läksyjä & 7 & Present & $\mathrm{C}+\mathrm{M}$ & Simultaneous \\
\hline \multicolumn{5}{|l|}{ "Tarja watching the TV Mari did homework." } \\
\hline \multicolumn{5}{|l|}{ [Tarja-gen watch-nonfinite-pres TV-ptv, } \\
\hline Tarjan katsottua televisiota Mari teki läksyjä & 8 & Past & $\mathrm{C}+\mathrm{M}$ & Chronological \\
\hline \multicolumn{5}{|l|}{$\begin{array}{l}\text { "Tarja having watched the TV Mari did } \\
\text { homework." }\end{array}$} \\
\hline \multicolumn{5}{|l|}{ [Tarja-gen watch-nonfinite-past TV-ptv Mari } \\
\hline do-past-progr. home-work] & & & & \\
\hline
\end{tabular}

Note. $\mathrm{M}=$ main clause; $\mathrm{S}=$ subordinate clause; $\mathrm{C}=$ converb; progr. $=$ progressive form; gen $=$ genitive; pres $=$ present tense; ptv $=$ partitive; past $=$ past tense; nonfinite $=$ nonfinite form.

clause orders: main clause preceding the subordinate clause/ converb construction $(M+S / C)$ and vice versa $(S / C+M)$. Sentences with temporal conjunctions ennen kuin "before" and sen jälkeen kun "after" presented two sequential events encoded either in chronological (Conditions 1 and 4) or in reverse chronological order (Conditions 2 and 3). The sentences with temporal converb constructions presented two events occurring either simultaneously (Conditions 5 and 7) or sequentially (Conditions 6 and 8). In the sequential conditions, the order of events was either chronological or reverse. The actions described in the sentences were commonly occurring concrete events familiar to the children.

As we aimed to examine children's ability to comprehend linguistic encoding of event order in situations in which they would not be able to rely on event-order plausibility (Pyykkönen et al., 2003; van der Meer et al., 2002), neither the experimental nor the filler items included event pairs that are causally or frequently co-occurring, thus preventing inferential reasoning of the event order based on world knowledge (Bloom, Fletcher, van den Broek, Reitz, \& Shapiro, 1990; Schaeken, Johnson-Laird, \& d'Ydewalle, 1996). ${ }^{2}$ In addition, in order to avoid the memory constraints that children may face in the act-out tasks used in the earlier studies (see, e.g., Trosborg, 1982, for a review of these studies), written sentences combined with comprehension questions were used without imposing a time limit. Comprehension questions have been found to be indicative of the correctness of the final interpretation created of the stories (see, e.g., Christianson, Williams, Zacks, \& Ferreira, 2006, for comprehension questions that revealed incorrect interpretations of garden-path sentences with younger and older adults).

\section{Design and Procedure}

Forty written sentences were created, five in each condition (see Table 1), counterbalanced in four questionnaires. Forty fillers depicting two simultaneous or sequential events, but not including

\footnotetext{
${ }^{2}$ Authors' own intuition was used to determine the lack of causality in the experiment. Same actions were also used in the earlier study by the same authors (Pyykkönen et al., 2003). Examples of these sentences can be found in Table 1 and in Footnote 3. As can be seen, the two actions do not appear in any particular order (or are even frequently co-occurring in any obvious way) in real life.
} 
temporal subordinate clauses or converbs, were added to each list. ${ }^{3}$ Participants were tested in groups, each grade at a time. Their task was to indicate which of the events occurred earlier, or whether they occurred at the same time, by circling either the correct verb or the alternative "same time"; all three alternatives were listed after the target sentence (see Example 2 below).

Example 2: ILKKA LUKI KIRJEEN ENNEN KUIN MENI KOULUUN. LUKI MENI YHTÄ AIKAA

"ILKKA READ THE LETTER BEFORE HE WENT TO SCHOOL. READ WENT AT THE SAME TIME."

In the main experimental items, the proportion of correct first and second versus same-time responses was $120(60+60)$ to 40 . This ratio was repeated in the filler items (40:10). The experiment took 30-40 (oldest-youngest) min to complete. Background information including children's age and language(s) used at home (indicating their mother tongue) were collected, and their reading abilities, as indicated by their school reports, were checked before the experiment by their teacher.

\section{Results}

Before data analyses, we removed empty responses ( 8 years, $2.2 \%$; 10 years, $0.6 \%$; 12 years, $0.3 \%)$. We coded the remaining responses as correct or incorrect. Because of its suitability for assessing categorical response variables, we inspected the data by fitting a generalized linear mixed model (with $R$ s lmer function and binomial family) to the responses (correct, incorrect) with age $(8,10,12)$, clause order $(M+S / C, S / C+M)$, and clause type (subordinate, converb) as fixed predictors. Items and participants were treated as a crossed-random factor in order to allow bysubject and by-item variation in one model (e.g., Baayen, 2008; Jaeger, 2008). We started with the full model described above. Due to differences in individual participant's performance in the two construction types, we included by-subject random slopes for clause type. The by-subject random slopes contributed to the model significantly compared with the model without them, as indicated by a likelihood test of model comparison, $\chi^{2}(2)=$ 44.146, $p<.001$, whereas dropping any interactions did not (all $p s>.3$ ). The full model is summarized in Table 2 .

Apart from age that showed a clear improvement in performance from younger to the older groups, there were no main effects, indicating that neither clause type nor clause order alone explained the difficulties. However, there was a significant interaction between clause type and clause order. In order to further investigate the cause of this interaction, we analyzed temporal subordinate clauses and converb constructions separately. We conducted separate analyses because the two sentence types included different types of event structures: Whereas the sentences with subordinate clauses coded only sequential events, sentences with converb constructions coded both simultaneous and sequential events.

\section{Subordinate Clauses}

The model with age, clause order, and conjunction (before/after) as predictors, and items and participants as a crossed-random factor, is summarized in Table 3 and the results depicted in Figure 1. The results revealed improved performance between the youngest and oldest groups. Children also performed better both when
Table 2

Summary of the Fixed Effects for the Model Response

\begin{tabular}{lrrr}
\hline \multicolumn{1}{c}{ Predictor } & Estimates & SE & Wald $Z$ \\
\hline Intercept & 2.966 & 0.359 & \multicolumn{1}{c}{$8.245^{* * * *}$} \\
Age(8) & -1.442 & 0.449 & $-3.208^{* * *}$ \\
Age(10) & -0.841 & 0.456 & $-1.843^{\dagger}$ \\
ClauseType(S) & -0.319 & 0.352 & -0.907 \\
ClauseOrder(S/C + M) & 0.291 & 0.279 & 1.042 \\
Interactions & & & \\
Age(8):ClauseType & 0.485 & 0.419 & 1.155 \\
Age(10):ClauseType & 0.738 & 0.437 & $1.689^{\dagger}$ \\
Age(8):ClauseOrder & 0.319 & 0.333 & 0.961 \\
Age(10):ClauseOrder & 0.132 & 0.341 & 0.388 \\
ClauseType:ClauseOrder & 0.988 & 0.459 & $2.150^{*}$ \\
Age(8):ClauseType:ClauseOrder & -0.963 & 0.530 & $-1.817^{\dagger}$ \\
Age(10):ClauseType:ClauseOrder & -0.949 & 0.553 & $-1.716^{\dagger}$ \\
\hline
\end{tabular}

Note. $N=5,223$. Estimates report coefficients for the fixed effects, and $p$ values were obtained from $z$ statistics. Age $\times$ ClauseOrder $\times$ ClauseType $+(1+$ ClauseTypelparticipant $)+(1$ litem $)$. Log likelihood $=-1,788$. The intercept terms (reference levels) were as follows: Age $=12$; Clause Type $=$ Main; Clause Order $=\mathrm{M}+\mathrm{S} / \mathrm{C}$. S $=$ subordinate clause; $\mathrm{S} / \mathrm{C}+$ $\mathrm{M}=$ subordinate clause or converb construction followed by main clause. ${ }^{\dagger} p<.1$. ${ }^{*} p<.05$. ${ }^{* * *} p<.01 .{ }^{* * *} p<.001$.

the main clause followed the subordinate clause, as was hypothesized on the basis of the earlier studies, and when the conjunction was before rather than after, a result also found in the earlier studies. Importantly, however, the interaction revealed no difference between the conjunctions (before/after) when the subordinate clause preceded the main clause (coefficient $=-0.044, Z<1$ ), whereas when the main clause preceded the conjunction, after was comprehended significantly worse than before (coefficient = $-2.320, Z=-9.58, p<.001)$. This tendency was most pronounced in the youngest group $(65 \%, 80 \%$, and $83 \%$ correct responses across age groups, respectively). These results suggest that when the information of how to order the events is given sentence initially, children are able to perform equally well in spite of whether the events were coded in chronological or reverse order. However, when the sentence-medial conjunction indicated reverse event order, children faced difficulties in constructing the correct situation model.

\section{Converb Constructions}

The model with age, event order (simultaneous/sequential), and clause order as predictors, and items and participants as a crossedrandom factor, is summarized in Table 4 and the results depicted in Figure 2. Again 8-year-olds' performance was worse than in the oldest age group. Better performance was also found during simultaneous than sequential sentences, indicating that simultaneity was easier to interpret in all age groups than sequentiality, whether chronological or reverse. However, the observed significant interaction between the 8-year-old group and event order also showed that in this age group, sequential events were interpreted relatively

\footnotetext{
${ }^{3}$ Examples of filler sentences: Pekka, joka haki Juhan, soitti pianoa ("Pekka, who fetched Juha, played the piano.") and Tänään Nelli paistoi kalaa ja eilen hän keitti keittoa ("Today Nelli fried fish and yesterday she made a soup.").
} 
Table 3

Summary of the Fixed Effects for Sentences With Temporal Subordinate Clauses

\begin{tabular}{lrrr}
\hline \multicolumn{1}{c}{ Predictor } & Estimates & \multicolumn{1}{c}{$S E$} & Wald $Z$ \\
\hline Intercept & 2.085 & 0.321 & $6.491^{* * *}$ \\
Age(8) & -1.234 & 0.389 & $-3.167^{* *}$ \\
Age(10) & -0.132 & 0.406 & -0.325 \\
ClauseOrder(S + M) & 2.040 & 0.511 & $3.988^{* * *}$ \\
Conjunction(Before) & 2.202 & 0.550 & $4.004^{* * *}$ \\
Interactions & & & \\
Age(8):ClauseOrder & -0.313 & 0.581 & -0.539 \\
Age(10):ClauseOrder & -1.061 & 0.596 & $-1.781^{\dagger}$ \\
Age (8):Conjunction & 0.398 & 0.647 & 0.615 \\
Age(10):Conjunction & -0.163 & 0.685 & -0.238 \\
ClauseOrder:Conjunction & -2.183 & 0.846 & $-2.580^{* *}$ \\
Age(8):ClauseOrder:Conjunction & -0.654 & 0.962 & -0.680 \\
Age(10):ClauseOrder:Conjunction & 0.654 & 1.011 & 0.602 \\
\hline
\end{tabular}

Note. $\quad N=2,609$. Log likelihood $=-748.8$. Estimates report coefficients for the fixed effects, and $p$ values were obtained from $z$ statistics. The intercept terms (reference levels) were as follows: Age $=12$; Clause Order $=\mathrm{M}+\mathrm{S}$; Conjunction $=$ After; $\mathrm{S}+\mathrm{M}=$ subordinate clause followed by main clause.

${ }^{\dagger} p<.1{ }^{* *} p<.01 .^{* * *} p<.001$.

worse than simultaneous ones. Even though the further three-way interaction with 8-year-olds was only marginal, it nevertheless looks like the difference in performance between the sequential events in the two clause orders underlies this result, especially because there is no observable difference in the simultaneous events between the two clause orders. Compared with the other age groups, then, it seems like 8-year-olds performed slightly worse when the sequential order coded reverse events than when it coded chronological events (see Figure 2), reaching only $61 \%$ correct compared with $82 \%$ accuracy in the oldest group (coefficient $=$ $-0.801, Z=-4.689, p<.001)$. Notably, then, as clause order alone failed to emerge as a significant predictor, it suggests that performance differences were not due to the main clause preceding the converb construction, or vice versa. Instead, sequential order
Table 4

Summary of the Fixed Effects for Sentences With Converb Constructions

\begin{tabular}{lrrr}
\hline \multicolumn{1}{c}{ Predictor } & Estimates & SE & \multicolumn{1}{c}{ Wald $Z$} \\
\hline Intercept & 5.173 & 0.664 & \multicolumn{1}{c}{$7.795^{* * * * *}$} \\
Age(8) & -2.590 & 0.755 & $-3.431^{* * * * *}$ \\
Age(10) & -0.867 & 0.797 & -1.088 \\
Event(Sequential) & -2.420 & 0.598 & $-4.041^{* * * *}$ \\
ClauseOrder(M + C) & -0.747 & 0.672 & -1.113 \\
Interactions & & & \\
Age(8):Event & 1.861 & 0.659 & $2.822^{* * *}$ \\
Age(10):Event & 0.014 & 0.704 & 0.020 \\
Age(8):ClauseOrder & 0.705 & 0.730 & 0.966 \\
Age(10):ClauseOrder & 0.262 & 0.784 & 0.335 \\
Event:ClauseOrder & 0.508 & 0.752 & 0.676 \\
Age(8):Event:ClauseOrder & -1.584 & 0.843 & $-1.878^{\dagger}$ \\
Age(10):Event:ClauseOrder & -0.560 & 0.893 & -0.627 \\
\hline
\end{tabular}

Note. $\quad N=2,614$. Log likelihood $=-886.8$. Estimates report coefficients for the fixed effects, and $p$ values were obtained from $z$ statistics.The intercept terms (reference levels) were as follows: Age $=12$; Event $=$ Simultaneous; Clause Order $=$ Converb + Main; $\mathrm{M}+\mathrm{C}=$ Main clause followed by converb construction.

${ }^{\dagger} p<.1 .{ }^{* *} p<.01 .^{* * * *} p<.001$.

was harder to interpret when the main clause preceded the converb construction than when the converb construction preceded the main clause. In other words, when children encountered a sentence like (a): Mari teki läksyjä Tarjan katsottua televisiota ("Mari did homework, Tarja having watched TV"; see Table 1), they had more trouble interpreting the relative timing of the events than with sentences like (b): Tarjan katsottua televisiota Mari teki läksyjä ("Tarja having wathed TV, Mari did homework"). This indicates that when the crucial information as to how to interpret the order of the two events became available only with the second clause rather than being available immediately, as in (a) with respect to (b), children had problems in understanding the relative timing of the events. This finding further supports the conclusion that when the information of how to order events is given

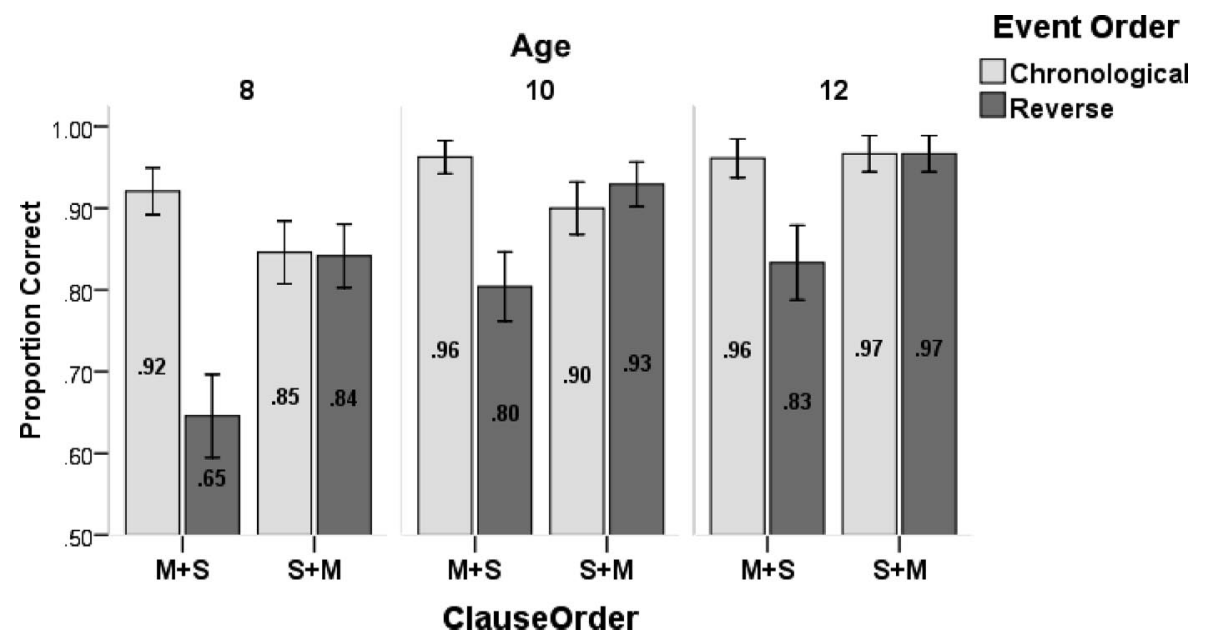

Figure 1. Proportion of correct responses for sentences with temporal subordinate clauses. Error bars represent $95 \%$ confidence intervals. $\mathrm{M}=$ main clause; $\mathrm{S}=$ subordinate clause. 


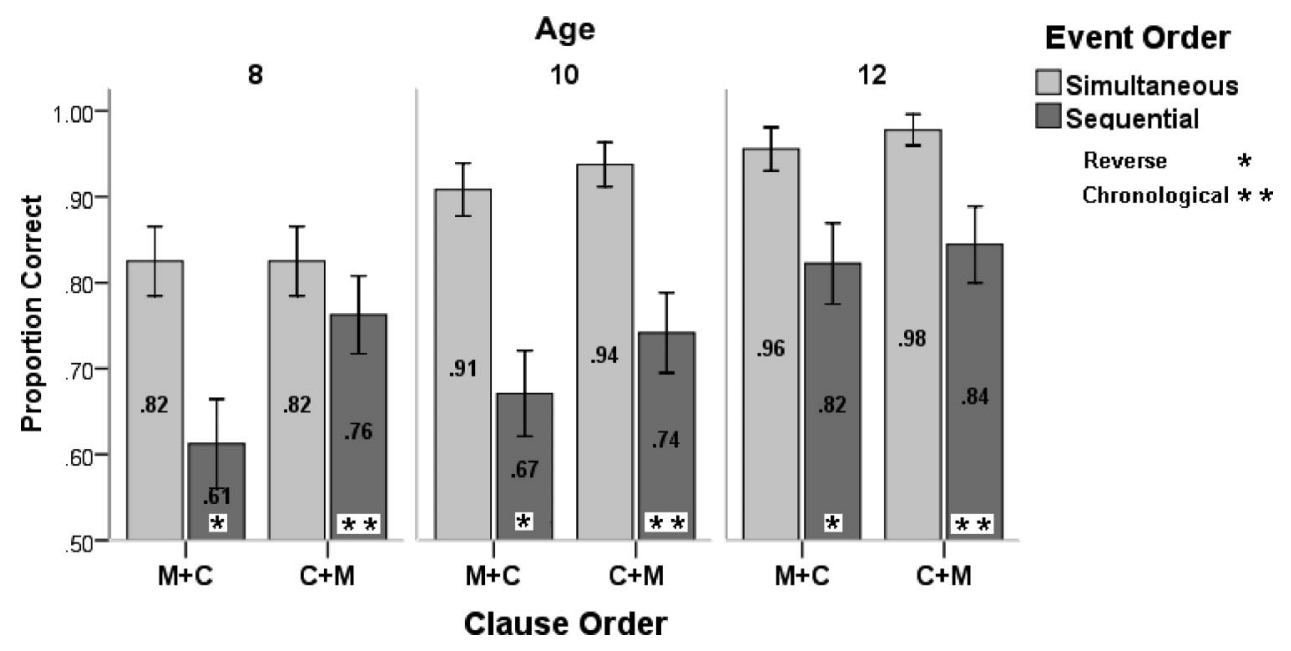

Figure 2. Proportion of correct responses for sentences with temporal converb constructions. Error bars represent $95 \%$ confidence intervals. $\mathrm{M}=$ main clause; $\mathrm{C}=$ converb.

sentence-medially, children face difficulties in constructing a correct situation model.

\section{Adult Comparisons}

In order to collect data from adults for a comparison, we administered the experiment to 12 adult native speakers. All were students at the University of Helsinki. The results showed only $1.7 \%$ of errors $(n=8)$ overall that were distributed across temporal subordinate clauses and converb constructions (overall $N=$ $240+240)$ as follows $(\%[n])$ : (a) temporal subordinate clauses: $\mathrm{M}+\mathrm{S}$ before (5.0 [3]); $\mathrm{M}+\mathrm{S}$ after (3.4 [2]); $\mathrm{S}+\mathrm{M}$ before $(0$ [0]); $\mathrm{S}+\mathrm{M}$ after (1.7 [1]); temporal converb constructions: $\mathrm{M}+$ $\mathrm{C}$ simultaneous (0 [0]); $\mathrm{M}+\mathrm{C}$ sequential (1.7 [1]); $\mathrm{C}+\mathrm{M}$ simultaneous (0 [0]); C $+\mathrm{M}$ sequential (1.7 [1]). Generalized linear mixed models (as above) showed no significant effects for any predictors (all Zs $<1$, all $p s>0.96$ ). These results suggest that adults did not show any difficulties in achieving a coherent situation model of the event orders in any of the possible linguistic encodings (see also Claus \& Kelter, 2006; Gennari, 2004; Münte et al., 1998).

\section{Discussion}

The study showed that children better succeeded in achieving the correct representation of the situation when language encoded events in the order they had occurred in the language-external world compared with reverse chronological encoding. Importantly, however, event order was not the sole predictor of children's performance. Instead, the timing of the cue of how to organize the events was crucial: When temporal subordinate conjunctions (before/after) or converb constructions were given sentence-initially, children were better able to arrive at the correct situation model than when the ordering information was given only later, sentencemedially. This was the case even if it required them to decode the linguistic information reversely with respect to the actual language external events.
Neither clause order nor the conjunction alone explained children's failures (cf. Amidon \& Carey, 1972; Clark, 1971; Feagans, 1980). Although comprehension was better when the main clause preceded the subordinate clause, this was not so with converb constructions. Even though converb constructions are morphologically more complex and less transparently separate from the main clause (due to the lack of conjunction indicating a clause boundary), children did not perform any worse with them than with the subordinate clauses. As the significant interaction between clause type and clause order suggests, even the older children did not perform as well with chronological converbs as they did with the temporal conjunctions. Overall, then, the results did not adhere to our predictions concerning morphosyntactic complexity. It seems, however, that in the case of sequential converbs, complexity matters: As the children got better at interpreting chronological versus reverse events, they were still struggling with the higher morphosyntactic complexity that renders converbs constructionally less opaque than the transparent conjunctions. In other words, we believe that the reason why the levels of performance on the reverse and chronological converbs, unlike on the subordinate clauses, appear to become more similar with increasing age is that whereas the children's ability to interpret time developed similarly across the age groups, as 12-year-olds' similar performance in reverse encoding in both clause types suggests, their ability to deal with syntactic complexity was not yet adultlike and hindered the 12-year-olds' interpretation of chronological events as well.

In general, children's ability to reach the correct interpretation of the situation increased with age. Interestingly, 8-year-olds were still only slightly above chance with sentences in which the reverse encoding was prompted in sentence-medial position, whereas the two older age groups performed significantly better, although still worse than in the other conditions. The effects showed that reverse encoding is in development across all age groups of the tested children. Further support for this claim was also found when comparing the performance with the adult participants who performed at the ceiling in all structures. Therefore, we can conclude that even the 12-year-old children were not perfectly adultlike in 
the task. Instead, it seems that constructing a situation model of multiple events requires a relatively long time to acquire.

\section{Event Order in Children's Situation Model}

In contrast to everyday life where people can often rely on observation when creating a representation of the events, similar temporal coupling is not possible when they have to create a representation of a series of events described in a text. Instead, comprehenders often need to wait until the text provides sufficient information (Fischer \& Zwaan, 2008; Zwaan, 1996, 2008). In this light, it is interesting that even in cases of forward-looking propositions, such as temporal structures or cataphors, people choose not to wait until all the required information is available before they start building the interpretation (Filik \& Sanford, 2008; Gennari, 2004; Münte et al., 1998). Our results suggest that children are less likely to reach the correct interpretation if this process is disrupted by information that requires them to revise the current representation of event order, as is the case with, for example, the sentence-medially presented conjunction after. Instead, when ordering information is available sentence-initially, children perform better-regardless of whether they need to build a chronological or reverse representation. This finding is consistent with the assumption that first-mentioned entities have a special role in situation models in laying the foundation to which the upcoming information is then mapped (e.g., Ferreiro \& Sinclair, 1971; Gernsbacher, 1989, 1990).

Earlier, Trosborg (1982) suggested that the reverse order signaled sentence-medially might lead children to produce a wrong action in the act-out task, because of their inability to stop producing the action they had already planned. However, with an act-out task, it cannot be resolved whether the incorrect response is a result of an inability to stop and revise the planned action or an inability to revise the actual linguistic interpretation, or a combination of both. Our study showed that children had difficulties in revising the mental representation of the two events if the reverse order was signaled sentence-medially, and more crucially, no difference was found between reverse and chronological order when the signal was present sentence-initially. It should also be noted that when the cue was present sentence-initially, it did not matter whether the correct answer required the identification of the main verb of the sentence or the verb in the subordinate clause, thus contrasting with the suggestion that children might fail in these types of tasks, because they do not code events in the main clause and in the subordinate clause to the same extent (Amidon \& Carey, 1972; Berman \& Slobin, 1994).

As shown by Münte et al. (1998), adults face temporary memory-based difficulties when the initially encountered event needs to be interpreted reversely with respect to the secondencountered encoded event (i.e., when before begins the sentence). We suggest in the present study that even if children face adultlike memory constraints, these alone cannot explain their failure to reach the correct interpretation, as children were equally good at reverse and chronological sentences when the critical conjunction was given sentence-initially. Moreover, it seems that comprehension is harder for (especially the younger) children when any ordering of the described events is required, as was shown by their much better performance in interpreting simultaneous events in contrast to sequential ones (see also Feagans, 1980).
Other studies have suggested that children might not be able to revise their initial sentence-parsing decisions because they are still developing their cognitive control abilities (e.g., Choi \& Trueswell, 2010; Trueswell, Sekerina, Hill, \& Logrip, 1999). These control mechanisms, as they are not fully developed, inhibit children from revising the interpretation that is already started. The studies suggesting these mechanisms as one source of sentenceparsing difficulties with children have investigated their performance with garden path instructions such as "Put the apple on the towel into the box" and shown that children under age 8 are unable to revise the interpretation they have already started to build (i.e., that the towel is not the location where the apple should be placed). In turn, children age 8 were able to successfully perform this revision (Trueswell et al., 1999; Weighall, 2008). If we assume that these control mechanisms underlie the explanation for children's failures in our study, it seems that these might take longer than until age 8 to become fully operational (see also V. Anderson, Anderson, Northam, Jacobs, \& Catroppa, 2001; Blakemore \& Choudhury, 2006, for discussions of the development of executive functions through childhood and adolescence).

However, the above explanation faces challenges from an interesting factor that was not considered in our study, namely, the plausibility of the incorrect interpretation. Earlier studies have shown that, just like adults, children use general world knowledge when comprehending time (French \& Brown, 1977; Pyykkönen et al., 2003; Radvansky et al., 1998; Trosborg, 1982; Zwaan, 1996, 2008). Thus, sentences such as "Mother fills the bottle before she feeds the baby" are easier for children to comprehend than "Mother fills the bottle before she washes her hands," because filling the bottle typically occurs before feeding the baby (Pyykkönen et al., 2003; Trosborg, 1982). In the latter case, the comprehension difficulty may be partly explained by a discontinuity in the story that might lead the comprehender to build two situation models that are later combined together in order to form a single model (Speer \& Zacks, 2005; Speer, Zacks, \& Reynolds, 2007; Zwaan, 1996, 2008; Zwaan \& Radvansky, 1998). In the present study, the two events were never actions that typically follow each other in a fixed order, and thus the degree of continuity or discontinuity among the sentences does not explain the present findings. However, the relatively high correct interpretation rate in conditions in which events were encoded in chronological order and in which the conjunction was given in the sentence-initial position suggests that children aimed to create the correct event order interpretation of these two events even though they were not causally related to each other. But again, children failed to do so when the cue was in the sentence-medial position and required revision of the situation model. However, as Christianson et al. (2006) have shown, event plausibility does play an important role in arriving at the coherent interpretation of the sentence or discourse in general. They gave younger and older adults garden-path sentences such as "While Mary bathed, the baby cried in the crib" and asked "Did Mary bathe the baby?" This resulted incorrectly in yes answers in both groups. This study suggests that even adults might fail to fully revise their interpretations when the sentences code events that could be plausible in the language-external world. These findings make it difficult to explain the challenge to revise the initial interpretation with undeveloped cognitive control mechanisms. Furthermore, it is unlikely that this explanation would account for our results completely, because with temporal subor- 
dinate conjunctions, the source of the error cannot be a syntactic misparse; rather, it lies in the misinterpretation of lexical-semantic information (conjunctions) with respect to the relative order of the events and the place of the conjunction. With converb constructions, however, the source could be morphosyntactic. As Christianson et al.'s study shows, semantic plausibility information can affect even adults' interpretation of the given event. Provided this much, if syntactic representation would underlie the errors in our case, we could expect the two sentence types to behave differently, because the potential source for the error is different: lexicalsemantic and morphosyntactic. As this was not the case, the more plausible explanation is that children (and adults in Christianson et al., 2006) failed to interpret the event structure correctly (i.e., failed to revise their situation model accordingly). Therefore, the difficulty does not necessarily lie in the undeveloped cognitive control mechanisms underlying sentence parsing, but instead at the level of creating the situation model of the events described by language. However, in order to further clarify the cognitive mechanisms that lead to the challenges in revising the situation model, it is of great interest for future studies to incorporate event plausibility into the event order encoding in children's language comprehension.

In summary, children experience difficulties in reaching the correct situation model of multiple events described in temporal sentences. Interestingly, this is still clearly the case with 8-yearolds, steadily improving with age. Crucially, these difficulties are gravest when the cue of how to order events is at the sentencemedial position and requires reverse chronological interpretation. This suggests that children's difficulties in comprehending sequential temporal events originate from their inability to revise the representation of the event they are building at the level of situation model.

\section{References}

Amidon, A. (1976). Children's understanding of sentences with contingent relations: Why are temporal and conditional connectives so difficult? Journal of Experimental Child Psychology, 22, 423-437. doi:10.1016/ 0022-0965(76)90106-5

Amidon, A., \& Carey, P. (1972). Why five-year-olds cannot understand before and after. Journal of Verbal Learning and Verbal Behavior, 11, 417-423. doi:10.1016/S0022-5371(72)80022-7

Anderson, V., Anderson, P., Northam, E., Jacobs, R., \& Catroppa, C. (2001). Development of executive functions through late childhood and adolescence in an Australian sample. Developmental Neuropsychology, 20, 385-406. doi:10.1207/S15326942DN2001_5

Anderson, A., Garrod, S. C., \& Sanford, A. J. (1983). The accessibility of pronominal antecedents as a function of episode shifts in narrative text. Quarterly Journal of Experimental Psychology, 35A, 427-440.

Baayen, R. H. (2008). Analyzing linguistic data: A practical introduction to statistics using R. Cambridge, UK: Cambridge University Press.

Berman, R., \& Slobin, D. (1994). Relating event in narrative: A crosslinguistic development study. Mahwah, NJ: Lawrence Erlbaum.

Blakemore, S.-J., \& Choudhury, S. (2006). Development of the adolescent brain: Implications for executive function and social cognition. Journal of Child Psychology \& Psychiatry, 47, 296-312. doi:10.1111/j.14697610.2006.01611.x

Bloom, C. P., Fletcher, C. R., van den Broek, P. W., Reitz, L., \& Shapiro, B. P. (1990). An on-line assessment of causal reasoning during comprehension. Memory \& Cognition, 18, 65-71. doi:10.3758/BF03202647

Choi, Y., \& Trueswell, J. C. (2010). Children's (in)ability to recover from garden-paths in a verb-final language: Evidence for developing control in sentence processing. Journal of Experimental Child Psychology, 106, 41-61. doi:10.1016/j.jecp.2010.01.003

Christianson, K., Williams, C. C., Zacks, R. T., \& Ferreira, F. (2006). Younger and older adults' "good-enough" interpretations of garden-path sentences. Discourse Processes, 42, 205-238. doi:10.1207/ s15326950dp4202_6

Clark, E. V. (1971). On the acquisition of the meaning of before and after. Journal of Verbal Learning and Verbal Behavior, 10, 266-275. doi: 10.1016/S0022-5371(71)80054-3

Claus, B., \& Kelter, S. (2006). Comprehending narratives containing flashbacks: Evidence for temporally organized representations. Journal of Experimental Psychology: Learning, Memory, and Cognition, 32, 1031-1044. doi:10.1037/0278-7393.32.5.1031

Diessel, H. (2004). The acquisition of complex sentences. Cambridge UK: Cambridge University Press. doi:10.1017/CBO9780511486531

Feagans, L. (1980). Children's understanding of some temporal terms denoting order, duration, and simultaneity. Journal of Psycholinguistic Research, 9, 41-57. doi:10.1007/BF01067301

Ferreiro, E., \& Sinclair, H. (1971). Temporal relationships in language. International Journal of Psychology, 6, 39-47. doi:10.1080/ 00207597108247296

Filik, R., \& Sanford, A. J. (2008). When is cataphoric reference recognised? Cognition, 107, 1112-1121. doi:10.1016/j.cognition.2007.11.001

Fischer, M. H., \& Zwaan, R. A. (2008). The role of motor system in language comprehension. Quarterly Journal of Experimental Psychology, 61, 825-850. doi:10.1080/17470210701623605

French, L. A., \& Brown, A. L. (1977). Comprehension of before and after in logical and arbitrary sequences. Journal of Child Language, 4, 247 256. doi:10.1017/S0305000900001641

Friedman, W. J., \& Seely, P. B. (1976). The child's acquisition of spatial and temporal word meanings. Child Development, 47, 1103-1108. doi: $10.2307 / 1128448$

Gennari, S. P. (2004). Temporal references and temporal relations in sentence comprehension. Journal of Experimental Psychology: Learning, Memory, and Cognition, 30, 877-890. doi:10.1037/02787393.30.4.877

Gernsbacher, M. A. (1989). Mechanisms that improve referential access Cognition, 32, 99-156. doi:10.1016/0010-0277(89)90001-2

Gersbacher, M. A. (1990). Language comprehension as structure building. Hillsdale, NJ: Lawrence Erlbaum Associates.

Haspelmath, M. (1994). Passive participles across languages. In B. Fox \& P. Hopper (Eds.), Voice: Form and function (pp. 151-177). Amsterdam, the Netherlands: John Benjamins.

Haspelmath, M. (1995). The converb as a cross-linguistically valid category. In M. Haspelmath \& E. König (Eds.), Converbs in cross-linguistic perspective: Structure and meaning of adverbial verb forms - adverbial participles, gerunds (pp. 1-55). Berlin, Germany: Mouton de Gruyter.

Jaeger, T. F. (2008). Categorical data analysis: Away from ANOVAs (transformations or not) and towards logit mixed models. Journal of Memory and Language, 59, 434-446. doi:10.1016/j.jml.2007.11.007

Johnson, H. L. (1975). The meaning of before and after for preschool children. Journal of Experimental Psychology, 19, 88-99.

Mandler, J. M. (1986). On the comprehension of temporal order. Language and Cognitive Processes, 1, 309-320. doi:10.1080/01690968608404680

Münte, T. F., Schiltz, K., \& Kutas, M. (1998, September 3). When temporal terms belie conceptual order. Nature, 395, 71-73. doi:10.1038/ 25731

Pyykkönen, P., Niemi, J., \& Järvikivi, J. (2003). Sentence structure, temporal order and linearity: Slow emergence of adult-like syntactic performance in Finnish. SKY Journal of Linguistic, 16, 113-138.

Radvansky, G. A., Zwaan, R. A., Federico, T., \& Franklin, N. (1998). Retrieval from temporally organized situation models. Journal of Ex- 
perimental Psychology: Learning, Memory, and Cognition, 24, 12241237. doi:10.1037/0278-7393.24.5.1224

Schaeken, W., Johnson-Laird, P. N., \& d'Ydevalle, G. (1996). Mental models and temporal reasoning. Cognition, 60, 205-234. doi:10.1016/ 0010-0277(96)00708-1

Speer, N. K., \& Zacks, J. M. (2005). Temporal changes as event boundaries: Processing and memory consequences of narrative time shifts. Journal of Memory and Language, 53, 125-140. doi:10.1016/ j.jml.2005.02.009

Speer, N. K., Zacks, J. M., \& Reynolds, J. R. (2007). Human brain activity time-locked to narrative event boundaries. Psychological Science, 18, 449-455.

Trosborg, A. (1982). Children's comprehension of 'before' and 'after' reinvestigated. Journal of Child Language, 9, 381-402.

Trueswell, J. C., Sekerina, I., Hill, N. M., \& Logrip, M. L. (1999). The kindergarten-path effect: Studying on-line sentence processing in young children. Cognition, 73, 89-134. doi:10.1016/S0010-0277(99)00032-3

van der Meer, E., Beyer, R., Heinze, B., \& Badel, I. (2002). Temporal order relations in language comprehension. Journal of Experimental Psychol- ogy: Learning, Memory, and Cognition, 28, 770-779. doi:10.1037/ 0278-7393.28.4.770

Weighall, A. (2008). On still being led down the kindergarten path Children's processing of structural ambiguities. Journal of Experimental Child Psychology, 99, 75-95. doi:10.1016/j.jecp.2007.10.004

Zwaan, R. A. (1996). Processing narrative time shifts. Journal of Experimental Psychology: Learning, Memory, and Cognition, 22, 1196-1207. doi:10.1037/0278-7393.22.5.1196

Zwaan, R. A. (2008). Time in language, situation models, and mental simulations. Language Learning, 58, 13-26. doi:10.1111/j.14679922.2008.00458.x

Zwaan, R. A., \& Radvansky, G. A. (1998). Situation models in language comprehension and memory. Psychological Bulletin, 123, 162-185. doi:10.1037/0033-2909.123.2.162

Received May 5, 2010

Revision received June 9, 2011

Accepted July 14, 2011 